Conservar este tipo de obras supone acercarse a un campo demasiado heterogéneo como para plantear procedimientos generales, fuera de lo que son metodologías de estudio propias del arte contemporáneo.Esportanto necesarioentenderconqué y cómo pueden estar hechas las obras, algo ineludible para proponer tratamientos tanto conservativos como restaurativos, ya sean consolidaciones, limpiezas, protecciones o planteamientos más agresivos y discutibles como los arranques.

Este texto se centrará exclusivamente en obras pintadas sobre muros y elementos urbanos, consideradas de forma popular como arte urbano. Los materiales pictóricos utilizados han evolucionado en los más de cuarenta años que vienen produciéndose estas obras, cambiando tanto las motivaciones en su elección, como las formulaciones que se emplean en su producción comercial.

\section{Objetivos y metodología}

El arte urbano como objeto de estudio es muy amplio y los materiales y técnicas empleados, aun acotando el estudio en los pictóricos, no lo son menos. La diversidad obliga a una primera aproximación que permita plantear una visión panorámica, asumimos que incompleta, para, sobre ella, plantear futuros estudios específicos.

Por tanto, en esta aproximación, se plantean los siguientes objetivos:

- Identificar las tipologías de pintura más habituales empleadas.

-Establecer una cronología en la evolución comercial de algunos de los productos más comunes.

-Conocer los principales aglutinantes que utilizan estas pinturas.

-Establecer tipologías de superficies pictóricas en relación a los principales aglutinantes de sus composiciones y el medio en el que se presentan. - Identificar vías de estudio necesarias para abordar procesos de conservación específicos para este tipo de obras.

El estudio se fundamentará en: la revisión de textos y publicaciones de expertos en el estudio de la evolución de estas prácticas; la consulta de blogs y páginas web de artistas, así como de entrevistas publicadas por distintos medios; páginas web y publicaciones corporativas de empresas productoras y suministradoras de los productos; estudios de identificación de materiales procedentes de las ciencias forenses, que tratan estas actuaciones como actos vandálicos y del ámbito de la conservación de patrimonio que han comenzado a interesarse en este tipo de obras.

\section{1-Herramientas y técnicas utilizadas: elección y evolu- ción}

Existen numerosos estudios que explican la evolución de la subcultura del grafiti hacia el postgraffiti y arte urbano desde un punto de vista sociológico y artístico, y algunos incluyen aspectos sobre las técnicas y herramientas empleadas, imprescindibles para comprender diferentes orientaciones en cada momento, como los de Castleman (1987), Sthal (2008), Lewishon (2008), Abarca (2010) y Waclaveck (2011), entre otros.

Tanto las herramientas y técnicas utilizadas, como sus usuarios, han cambiado mucho en estas décadas. Algunas comenzaron a usarse en los orígenes, manteniendo una línea evolutiva, y otras han aparecido por el camino ante las reorientaciones de la escritura y la pintura callejera.

Su elección viene determinada por muchos aspectos complementarios entre sí, relacionados tanto con la disponibilidad del material, como con el discurso, el lenguaje estético y la costumbre de quien la emplea, pero también puede vincularse a la propia evolución y transformación progresiva de la práctica, por lo que no se debe desvincular una cosa de la otra.

En los antecedentes y origen del grafiti las ideas de "dejarse ver" y "repetición" son fundamentales, lo que obliga a utilizar herramientas comunes e inmediatas, que permitan dejar la huella del paso por el lugar mediante un grafismo o una incisión. Esta es la motivación fundamental de las primeras firmas o tags, que junto con la ilegalidad de la acción, determina la necesidad de velocidad de ejecución. Los primeros materiales disponibles serán además de tizas y ceras, poco permanentes, la pintura y la brocha, problemática para su transporte.

La popularización de las pinturas en aerosol en los cincuenta y sesenta, al orientar su mercado al ámbito doméstico, proporcionó una herramienta eficaz, que cumplía con todos esos requisitos. Los rotuladores de tinta permanente, en fechas similares, posibilitaron la inmediatez de la firma y su aplicación sobre múltiples superficies. Sin embargo, es la lata de pintura en espray la que se ha convertido en un icono de esta subcultura, influyendo para algunos de forma determinante en la transformación de la propia práctica y por tanto en su evolución como movimiento cultural y artístico (Weide, 2006).

La pintura en aerosol ofrece inmediatez, comodidad, facilidad de transporte, permanencia y adaptación a todo tipo de superficies. Posibilita utilizar colores diferentes de forma rápida y cómoda, con nuevas opciones. Todo esto influye en que las firmas se vayan sofisticando, sus cualidades estéticas adquieren protagonismo, ocupando cada vez más espacio y desarrollando estilos concretos. La repetición no es ya el elemento principal. Aparecen obras mucho más elaboradas o piezas, realizadas sobre vagones, muros y superficies más grandes, que despertarán el 
interés social y crítico, publicándose muchos libros que recopilan sus imágenes contribuyendo a su conocimiento y expansión, como el de Castleman (1982) o el de Chalfant y Prigoff, (1987).

En los años ochenta, la subcultura del grafiti, su atractivo y difusión, hace que pintar en la calle vuelva a resultar interesantey, con y sin permiso, jóvenes de diversos círculos artísticos lo practican con distintos pero confluyentes intereses y finalidades, Keith Haring o Kenny Scharf son ejemplos de ello (Kolossa, 2004). El espray continuará siendo una herramienta útil y simbólica, pero, sobre todo, en obras comisionadas por galeristas e iniciativas privadas, determinadas características que ofrece dejarán de ser imprescindibles. Algunas comienzan a realizarse con brocha y pintura, del ámbito de la construcción y el sector doméstico y decorativo, especialmente cuando se van a cubrir grandes superficies, resultando mucho más cómodas y económicas que las latas de aerosol. Probablemente influyen también los programas como The city of Philadelphia Mural Arts Program, a mediados de esa década, orientado a redirigir a jóvenes con inquietudes artísticas, que se iniciaban en el grafiti y la cultura Hip Hop, hacia obras comisionadas institucionalmente, de grandes dimensiones y con carácter comunitario'. Estos programas, desarrollados en varias ciudades, derivaron en la popularización del mural en la calle a gran escala así como en el uso de otros materiales, como emulsiones acrílicas de más calidad y pinturas al silicato, buscando una perdurabilidad en las obras.

Aún con todo, el espray seguiría siendo una de las herramientas preferidas, tanto por la clandestinidad que permite, como por su estética y simbolismo. Hasta finales de los noventa los aerosoles empleados procedían, del sector doméstico o la automoción, pero con la irrupción en el mercado en 1994 de la empresa española Montana Colors comienza una línea de producción específica de pintura en spray destinada a cubrir los requisitos que los artistas y escritores buscan en el material. Su éxito durante la siguiente década provoca el desarrollo de otras marcas y líneas que facilitan la expansión del movimiento y abren el campo de la creación propiamente artística.

Para entonces la subcultura del grafiti y sus derivaciones se habían expandido de forma global y se había escrito, fotografiado y filmado mucho sobre ella. En cada contexto geográfico y social seguirá una evolución local propia, con notas comunes, pero grandes particularidades, que también ha sido estudiada ampliamente en investigaciones específicas, como en el contexto europeo por Bart Bosmans y Axiel Thiel (Bosmans y Thiel, 1995), en el español por Gabriela Berti, (Berti, 2009) o en el madrileño por Fernando Figueroa y Felipe Gálvez (Figueroa y Gálvez, 2002).

La importancia de las firmas y piezas de los orígenes darán paso también al mensaje icónico a través de la imagen y en esto el uso de la plantilla o stencil será determinante.
Esta técnica permite la repetición, pero también posibilita la ejecución de imágenes potentes, sin autorización, en un tiempo récord. De nuevo el spray facilita la tarea. Estas imágenes cargadas de ironía conectan muy bien con la gente y aunque la técnica ya se realizaba desde los ochenta, figuras como Bleck Le Rat y Bansky contribuirán a la popularización y también a la mediatización de este tipo de prácticas.

Como señala Jaume Gómez, en su percepción como arte han contribuido tanto museos, como instituciones educativas, así como las redes sociales e internet (Gómez, 2014: 26). Desde finales del XX muchos jóvenes artistas en formación conocen estas prácticas en los contextos académicos $y$, con una perspectiva diferente, también deciden salir a pintar al entorno urbano, experimentando tanto con materiales propios del ámbito como con aquellos utilizados durante su formación. Por otra parte, la popularización en los medios mantiene esa conexión con el sector juvenil que revive los primeros pasos de los sesenta varias décadas después y en un contexto diferente, pero experimentando las mismas técnicas con otros materiales.

La fama de ciertas figuras emblemáticas que actúan en la clandestinidad favorece la permisividad hacia este tipo de prácticas, por lo que algunos artistas renuncian incluso a la ejecución veloz, planificando detenidamente la imagen y volviendo a técnicas como la pintura doméstica aplicada con brocha y rodillo. Además los planes de lucha contra el grafiti de algunos ayuntamientos como el de Salamanca ${ }^{2}$ fomentan la proliferación de convocatorias públicas de pinturas murales orientadas a artistas que pintan en la calle sin permiso, en las que los materiales, como sucede en festivales y exhibiciones, son proporcionados por la propia entidad organizadora, con productos de empresas distribuidoras locales.

En origen y puesto que el grafiti es también una forma de socialización, las técnicas se aprendían a través de la propia experimentación y el contacto directo con otros artistas. En la actualidad se organizan talleres y existen hasta recetarios de arte urbano como el publicado por Benke Carlsson y Hop Louie en 2010, traducido al español y reeditado por Gustavo Gili (Benke y Louie, 2013). Las redes sociales también se han convertido en un medio para compartir información y abundan los foros específicos. En definitiva, cada vez resulta más sencillo pintar en la calle y la profusión de imágenes satura al espectador.

La relación con el público resulta mucho más fluida, pero para no pasar desapercibidos han ido surgiendo todo tipo de herramientas y sistemas, que intentan explorar las posibilidades de comunicación en la calle, desde un punto de vista plástico o relacionado incluso con el propio discurso artístico. Cualquier elemento urbano es susceptible de ser utilizado como soporte o como excusa material sobre y con el que trabajar, desde una farola a un jardín. Las técnicas "tradicionales" se van sofisticando apareciendo productos específicamente orientados para 


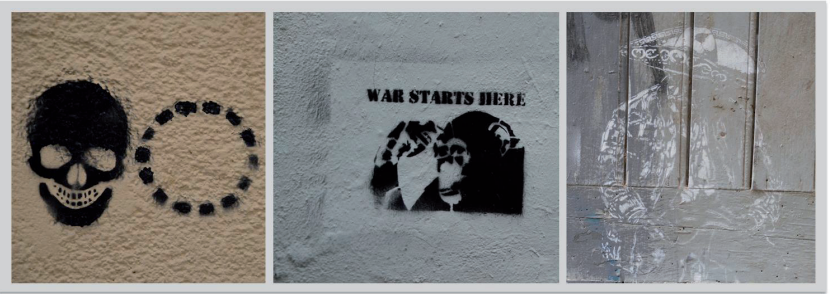

Figura 1. Obras elaboradas con espray y plantilla con diversos niveles de complejidad.

este uso, las plantillas elaboran trabajos verdaderamente complejos, como los de Cawamo e incluso la pintura puede ser propulsada con bombonas, como la krink ${ }^{\circledR}$ applicator de ocho litros, comercializada por la empresa Krink Inc. [Figura1]

Por tanto, las técnicas pictóricas más habituales en la actualidad se basan en el uso del espray o la pintura de brocha, aplicados de forma directa o indirecta a través de plantillas y reservas, sobre soportes diversos, preparados parcialmente en algunos casos y retocadas o combinadas con otras técnicas y materiales en ciertas ocasiones [Figura2].

Además de técnicas que podemos englobar entre las "pictóricas" se utilizan y desarrollan muchas otras que no se van a tratar en este estudio, pero que se podrían agrupar en las siguientes categorías:

-Técnicas sustractivas (como el scratching o el reverse graffiti, entre otras)

-Técnicas apropiativas (como el adbusting, entre otras)

-Técnicas aditivas (como las pegatinas o stickers, carteles e instalaciones, etc...)

\section{2-Principales materiales pictóricos empleados}

A lo largo de estas décadas los materiales disponibles han cambiado y evolucionado. Aún empleando la misma herramienta, el tipo de pintura aplicada puede tener una composición totalmente diferente.

A pesar de que ya se ha realizado alguna intervención sobre obras de arte urbano, como la llevada a cabo sobre una pintura de Haring en un ascensor de la escuela de Bellas Artes de Utrich (Beerkens y Mager, 2005), los recientes arranques realizados con motivo de la exposición Street Art. Banksy \& co. L'arte allo stato urbano (Ciancabilla, 2015) o los procesos que desarrolla el grupo St.a.co, en Grecia ${ }^{3}$, existen pocos estudios específicos centrados en el análisis de la composición de estos materiales, requisito imprescindible para plantear tratamientos compatibles y seguros.

La diversidad de materiales utilizados dificulta enormemente esta tarea, por lo que en este texto se intentará presentar un abanico de aquellos más comunes, agrupados en pinturas en espray, rotuladores comerciales y caseros y pintura doméstica, tratando de establecer tipologías y grupos, atendiendo a los estudios publicados hasta la fecha.

\section{1-Pintura en aerosol o espray}

\subsection{1-Orígenes}

La pintura en aerosol es una de las técnicas que identifican al grafiti y arte urbano. Sin embargo el espray no se refiere a un material concreto, tan sólo a una tecnología de aplicación y a un recipiente que puede contener diferentes tipos de pintura.

Uno de los factores que más impulsaron el desarrollo de esta tecnología y su aplicación en recipientes transportables fue la necesidad de proporcionar insecticidas a los soldados durante
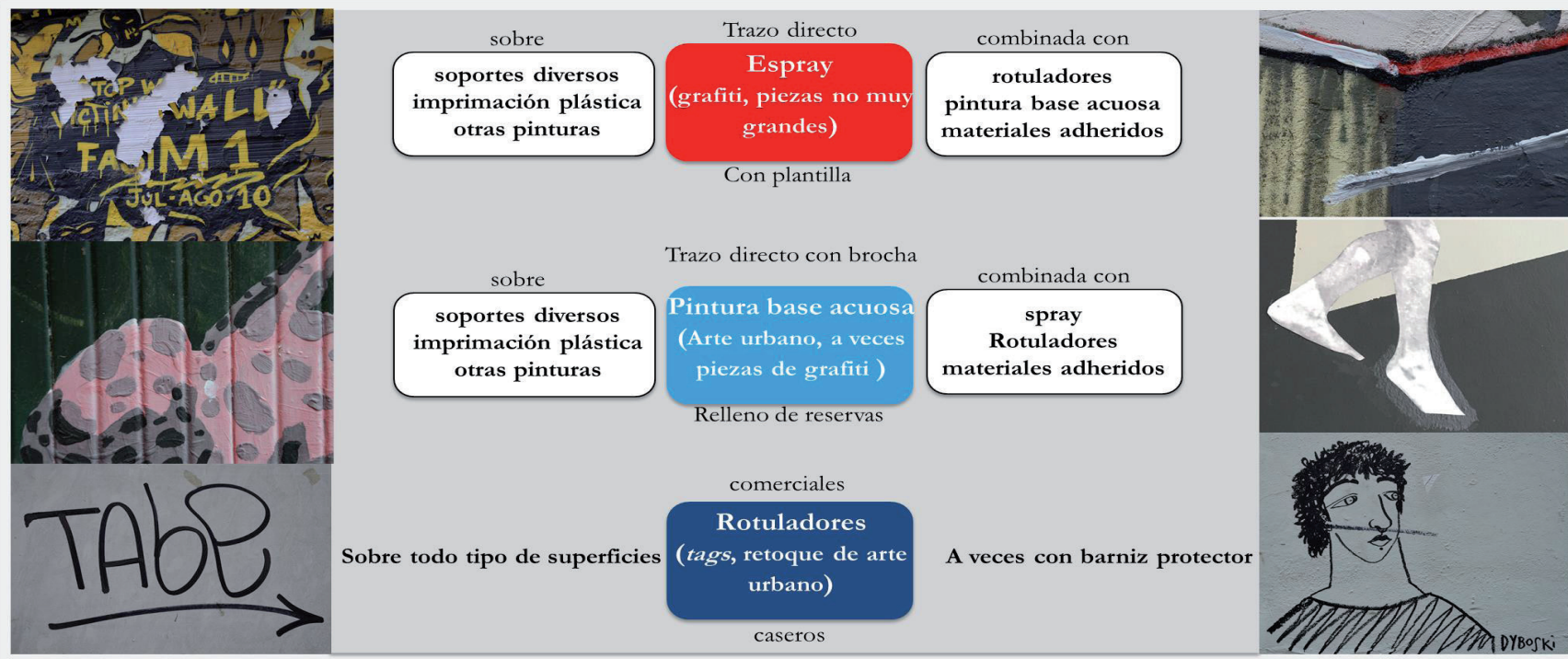

Figura 2. Técnicas pictóricas más comunes en el grafiti y arte urbano. Detalles de obras de Fasim, Lolo, Tag de Tabe, Dafne Tree, Big y Dyboski. 
la II Guerra Mundial (Shangraw, 1971:11). La válvula patentada por Robert Abplanalp (Abplanalp, 1953) permitió su aplicación para multitud de productos, aunque su uso como recipiente de pintura se debe a Edwar Seymour, fundador de la empresa Seymour ${ }^{\circledast}$ of Sycamour, Inc. en Chicago en $1949^{4}$.

Desde entonces se han desarrollado infinidad de marcas que comercializan pinturas presentadas de este modo, con distintos usos y finalidades, que han sido empleadas por escritores y artistas en distintos momentos.

\subsubsection{Marcas utilizadas}

En los inicios se empleaban esprays de marcas accesibles en el entorno inmediato, la mayor parte de las veces robadas en grandes almacenes y droguerías y será precisamente esta disponibilidad una de las principales influencias en su utilización.

A finales de los setenta y en los ochenta, en pleno apogeo de las guerras de estilo y las piezas más elaboradas, las marcas más utilizadas en el mercado americano eran las que se habían ido experimentando a través de las primeras firmas, comprobando su capacidad cubriente y su resistencia. La accesibilidad de productos como los de Rust-Oleum y Krylon ${ }^{\circledR 5}$, motivó que se utilizaran de forma habitual en América, adquiriendo un protagonismo vigente todavía en la actualidad (Gastman y Neelon, 2011:260). Es fácil ver sus botes en imágenes de esos años recogidos en los libros anteriormente citados. La variedad de productos europeos y americanos que surgieron en los sesenta, setenta y ochenta destinados a recubrimientos protectores, automoción y decoración es enorme y queda patente en algunas publicaciones como la realizada por el colectivo Cap Matches Colors, Two decades of Digging, fruto de un proyecto centrado en la colección, preservación y diseminación de la pintura en espray, especialmente orientado al mercado americano (CMC crew, 2015) y Aerosols, en la que Daniel "Rosko" bajo una óptica similar, presenta un recorrido por las marcas europeas comercializadas, especialmente en Alemania, entre los años 1965 a 1999, y que refleja la gran influencia de algunas como Belton o Sparvar , con su línea específica para grafiti Tuff Colors (Rosko, 2016). En las entrevistas recogidas en ambas publicaciones se puede comprobar también la tendencia de muchos artistas a mezclar diferentes marcas en la creación de una pieza.

En España los materiales también se roban, incluso para revender, tal y como recogen las múltiples entrevistas realizadas por Fernando Figueroa y Felipe Gálvez para documentar los libros Madrid Graffiti 1982-1995 y Firmas, muros y botes (Figueroa y Gálvez, 2002; 2014). En ellos también se incluyen referencias a algunas de las marcas más utilizadas por los españoles: Dupli-Colors ${ }^{\circledast}$, SprayColors o las míticas Novelty, marca ya desaparecida, producida por Weinco S.A (Moreno, 2016), nombradas también en documentales como el de Antoni Sendra sobre el grafiti valenciano (Sendra, 2007). Otras marcas que se citan y que se pueden ver en imágenes de redes sociales en las que comparten fotos de esas décadas, como la página de Facebook Novelty aerosoles, o el grupo Old School Madrid en Flickr ${ }^{6}$, son Altona, Bri-spray, Pictex retoke, CRC, Tamiya Color, Fellez y Mata, Solcolor, Wacolux o Felton Spray. [Figuras 3 y 4 ]

De la división española de esta última, Felton, procedía Jordi Rubio, quien junto con Miquel Galea y los grafiteros Kapi y Moockie revolucionarían la industria internacional de la pintura en aerosol, con la fundación de la empresa Montana Colors S.L. en 1994, reorientando su producción a los requisitos de los grafiteros: productos específicos, resistentes y cubrientes, con una amplia gama de colores, boquillas variadas y adecuadas a los distintos trazos a conseguir, y a un precio mucho más asequible. Esta revolución, venida del mundo de la industria, influirá en la transformación de la práctica ya que las posibilidades estéticas queofrecíanestos productosabríanunasexpectativastotalmente nuevas (Gastman y Neelon, 2011:260). Tal y como relatan en su web corporativa, en 1997 sus productos se distribuían por gran parte de Europa, y en 1999 en Estados Unidos, Canadá, México y Argentina. El éxito alcanzado llevará a que otras muchas empresas comiencen a producir líneas específicas, llegando incluso a tener que litigar por la conservación del nombre con su distribuidora alemana L\&G, fundadora junto con Duplicolor, de Montana Cans, en una maniobra que no hace sino destacar el interés despertado por la gama ofrecida y sus posibilidades de explotación comercial. Este tipo de producto irá asentándose durante los noventa, coexistiendo con otros muchos de los sectores antes mencionados, que continúan utilizándose, incluso en la actualidad.

De las marcas actuales destinadas específicamente al grafiti destacan por su apreciación entre los usuarios, Montana Colors, MontanaTM cans, Belton MolotowTM, Ironlak ${ }^{\oplus}$, Scribo ${ }^{\circledast}$, Clash $^{\circledR}$, FlameTM, Kobra $^{\circledR}$. [Tabla 1]

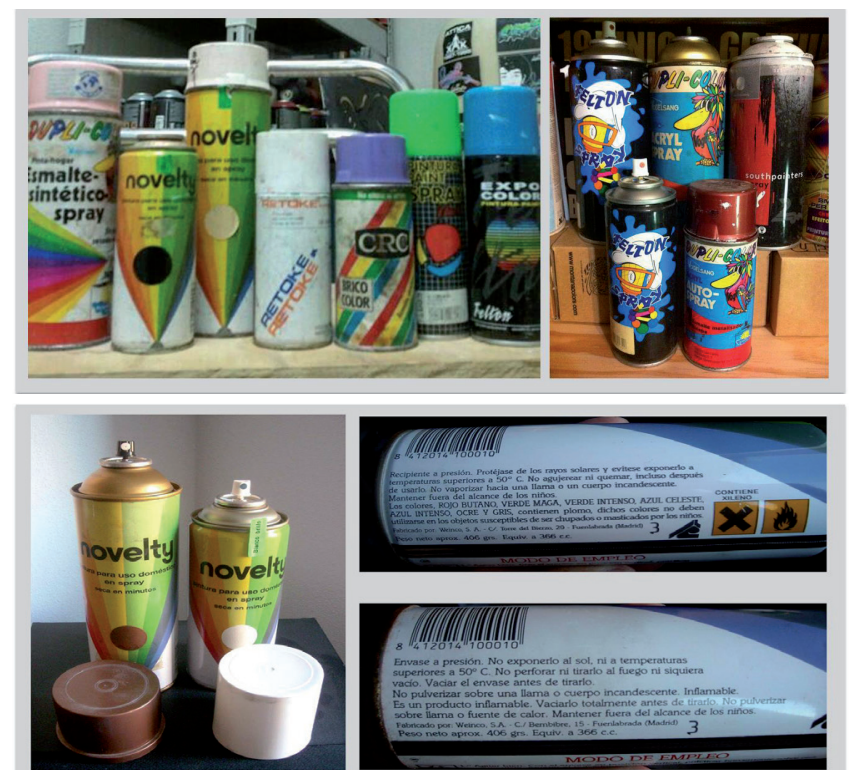

Figura 3 y4. Latas de aerosol de distintas marcas utilizadas por escritores madrileños en los 80 y 90 . Cortesía de Novelty aerosoles Facebook https://www.facebook.com/Novelty-aerosoles. 


\begin{tabular}{|c|c|c|}
\hline $\begin{array}{l}\text { MARCA Y EMPRESA DE } \\
\text { FABRICACIÓN }\end{array}$ & PRINCIPALES LÍNEAS DE PRODUCTO & $\begin{array}{l}\text { INFORMACIÓN PROPORCIONADA } \\
\text { POR EL FABRICANTE }\end{array}$ \\
\hline \multirow[t]{5}{*}{$\begin{array}{l}\text { MONTANA COLORS } \\
\text { Montana Colors S.L. España } \\
\text { www.montanacolors.com } \\
1994\end{array}$} & $\begin{array}{l}\text { Montana 94. } 189 \text { colores; Alier. } 23 \text { colores; Hardcore. } \\
109 \text { colores; Krink. } 2 \text { colores (blanco y negro); } \\
\text { Megacolors. } 12 \text { colores; Speed. } 25 \text { colores; TNT: } 7 \\
\text { colores }\end{array}$ & $\begin{array}{l}\text { Propelente: butano, propano } \\
\text { Ligante: resina alquídica modificada } \\
\text { Diluyente: mezcla aromática } \\
\text { Pigmentos: ver ficha técnica }\end{array}$ \\
\hline & Nitro $2 G$ & $\begin{array}{l}\text { Propelente: GLP C3-C4 } \\
\text { Diluyente: acetato de butilo } \\
\text { Pigmentos: ver ficha técnica }\end{array}$ \\
\hline & Nitro $2 G$ Colors 8 colores & $\begin{array}{l}\text { Diluyente: acetato de etilo } \\
\text { Pigmentos: ver ficha técnica }\end{array}$ \\
\hline & Mega Plata & $\begin{array}{l}\text { Propelente: butano, propano } \\
\text { Ligante: resina acrilica } \\
\text { Diluyente: mezcla aromática } \\
\text { Pigmentos: ver ficha técnica }\end{array}$ \\
\hline & Water-based 52 colores & $\begin{array}{l}\text { Ligante: PU modificado } \\
\text { Diluyente: agua y alcohol } \\
\text { Pigmentos: ver ficha técnica }\end{array}$ \\
\hline \multirow{3}{*}{$\begin{array}{c}\text { MONTANA }{ }^{\mathrm{TM}} \text { CANS } \\
\text { Duplicolor-Vogelsang / L\&G Vertrieb } \\
\text { GmbH } \\
\text { Alemania (origen) y China } \\
\text { https://www.montana-cans.com } \\
2002\end{array}$} & Gold. 215 colores & $\begin{array}{l}\text { Ligante: NC-acrilica } \\
\text { Diluyente: mezcla de solventes }\end{array}$ \\
\hline & Black (infra:36 colores; tarnegra; sylverchrome) & $\begin{array}{l}\text { Ligante: resina nitrocombinada } \\
\text { resina nitrocombinada con bitumen en Tar } \\
\text { acrilica en Sylverchrome } \\
\text { Diluyente: mezcla de solventes }\end{array}$ \\
\hline & White (51 colores) & $\begin{array}{l}\text { Ligante: resina sintética } \\
\text { Diluyente: mezcla de solventes }\end{array}$ \\
\hline \multirow{4}{*}{$\begin{array}{l}\text { BELTON MOLOTOW } \\
\text { Feuerstein GmbH } \\
\text { Belton/ Kwasny, Alemania } \\
\text { http://www.molotow.com } \\
1999\end{array}$} & $\begin{array}{l}\text { UrbanFine-Art }{ }^{\text {TM }} \\
\text { (Professionat } 48 \text { colores; Special. chalk ( } 10 \text { colores); neon } \\
\text { ( } 5 \text { colores); transparent }(5 \text { colores); phospbor ( } 1 \text { color); effect ( } 3 \\
\text { colores); metallic ( } 3 \text { colores) }\end{array}$ & $\begin{array}{l}\text { Ligante: base acrilica } \\
\text { Diluyente: mezcla de solventes } \\
\text { Pigmentos: ver ficha técnica }\end{array}$ \\
\hline & $\begin{array}{l}\text { Artist Line } \\
\text { (Premium } 251 \text { colores, One } 4 A \| I^{T M} \text { Acrylic } 24 \text { colores) }\end{array}$ & $\begin{array}{l}\text { Ligante: nitro-alquídica (Premium) } \\
\text { resina acrilica (ONE4ALL }{ }^{\mathrm{TM}} \text { Acrylic) } \\
\text { Diluyente: mezcla de solventes (Premium) } \\
\text { 85\% agua (ONE4AIL } L^{\mathrm{TM}} \text { Acrylic) }\end{array}$ \\
\hline & $\begin{array}{l}\text { Action Line } \\
\text { Hight Pressure: } 18 \text { colores; CoversAll }^{\text {TM: }} 49 \text { colores; } \\
\text { CoversAll1: solo negro; Coversall2. solo negro; } \\
\text { Burner }^{\text {TM: }} \text { : oro, plata, bronce; Devil Colors. sólo negro }\end{array}$ & $\begin{array}{l}\text { Ligante: nitro-alquídica (Hight Pressure); nitro-alquídica } \\
\text { con bitumen (CoversAll; Acnlica y bitumen(CoversAll1 y } \\
\text { CoversAll2 y CoversAll 3) } \\
\text { Diluyente: mezcla de solventes } \\
\text { Pigmentos: no especifica, Covers All3 con UV block }\end{array}$ \\
\hline & $\begin{array}{l}\text { Tech Line } \\
\text { (Phosphor. } 3 \text { colores (verde, naranja y azul); Pigment } \\
\text { Spray. } 10 \text { colores) }\end{array}$ & \\
\hline \multirow{2}{*}{$\begin{array}{c}\text { IRONLAK } \\
\text { AVT paints LCC } \\
\text { Hasta } 2008 \text { en Australia, ahora en China } \\
\text { https:// www.ironlak.com } \\
2004\end{array}$} & Ironlak ${ }^{2}$ (137 colores); Ironlak ${ }^{\otimes}$ Tar Paint (sólo negro) & $\begin{array}{l}\text { Ligante: resina acrilica (desde } 2008 \text { ) } \\
\text { Diluyente: mezcla de solventes }\end{array}$ \\
\hline & Sugar $^{\$}$ ( 40 colores) & $\begin{array}{l}\text { Ligante: resina acrilica } \\
\text { Diluyente: agua y alcohol }\end{array}$ \\
\hline $\begin{array}{l}\text { SABOTAZ }^{(2)} \\
\text { CL }^{80} \text { Cosmos lac s.a., Grecia } \\
\text { http://cosmoslac.com }\end{array}$ & Sabotaz $z^{8 * 120}$ colores & $\begin{array}{l}\text { Ligante: resina acrilica } \\
\text { Diluyente: mezcla de solventes }\end{array}$ \\
\hline $\begin{array}{l}\text { CLASH }^{\text {Q }} \\
\text { Colorpack s.r.1, Italia } \\
\text { www.clashpaint.com } \\
2001\end{array}$ & $\begin{array}{l}\text { Clash }^{8}: 100 \text { colores; Clash Tyson: } 4 \text { colores (negro, } \\
\text { blanco, rojo y plata) }\end{array}$ & $\begin{array}{l}\text { Ligante: resina acrilica } \\
\text { Diluyente: mezcla de solventes }\end{array}$ \\
\hline $\begin{array}{c}\text { SCRIBO }^{\circledR} \\
\text { Scribo Shop SAS, Italia } \\
\text { http://www.scriboshop.com }\end{array}$ & Scribo 2.45 colores & $\begin{array}{l}\text { Ligante: resina acrilica } \\
\text { Diluyente: mezcla de solventes }\end{array}$ \\
\hline $\begin{array}{c}\text { FLAME } \\
\text { Feuerstein GmbH, Alemania } \\
\text { Fabricada en Grecia por Cosmos lac S.L. } \\
\frac{\text { http://www.flame-paintcom }}{2011}\end{array}$ & $\begin{array}{l}\text { Orange } 48 \text { colores HP } \\
\text { Blue } 104 \text { colores LP }\end{array}$ & $\begin{array}{l}\text { Ligante: resina acrilica } \\
\text { Diluyente: mezcla de solventes }\end{array}$ \\
\hline $\begin{array}{l}\text { KOBRA }^{\circledR} \\
\text { Spraytec group, Italia } \\
\text { Fabricado por Ital G.E.T.E. }\end{array}$ & $\begin{array}{l}\text { Kobra } 400 \text { HP: } 132 \text { colores; Kobra } 400 \text { Low. } 80 \\
\text { colores; Fluo: } 6 \text { colores; Special. } 3 \text { colores, cobre, plata y } \\
\text { oro }\end{array}$ & $\begin{array}{l}\text { Ligante: resina } 100 \% \text { acrilica; Diluyente: mezcla de } \\
\text { solventes }\end{array}$ \\
\hline
\end{tabular}

Tabla 1. Marcas actuales más destacadas, destinadas específicamente al grafiti. 
Las grandes firmas americanas Rust-Oleum ${ }^{\circledast}$ y Krylon $^{\circledR}$, sin embargo, nunca han querido ofrecer una gama para el grafiti, precisamente por desvincular su marca y su logo de este tipo de prácticas, y han continuado su línea de producción orientada a los recubrimientos industriales y bricolaje. De hecho Krylon es actualmente criticada por muchos artistas por el cambio experimentado en sus prestaciones (CMC crew, 2016b).

Los productos genuinamente producidos para arte urbano se ofrecen como sistemas de baja o alta presión, en relación a su capacidad/velocidad de cubrición y a su facilidad y control de manejo. Cada marca ofrece varias líneas de producto orientadas a cubrir estas necesidades junto con otros aspectos estéticos. Las claves en el mercado actual son calidad, en cuanto a cubrición y resistencia, precio, posibilidad de control, variedad cromática y en los últimos años ecología y sostenibilidad.

\subsubsection{Naturaleza de sus componentes}

Como toda pintura la que contienen los espray está compuesta por combinaciones de aglutinantes, pigmentos, cargas y aditivos con distintas funciones, presentados en un vehículo adecuado para mantener la mezcla y en este caso con un propelente que posibilita su específica forma de aplicación. Al igual que en otros muchos sectores industriales de pinturas, las formulaciones han evolucionado, ajustando cada vez más la dosificación de sus componentes, con compensaciones específicas en relación al uso para el que son producidas y a cada color en particular.

Las más antiguas eran formuladas con una base de solvente orgánico, propelentes a partir de gases de clorofluorocarbonos, hasta su prohibición en 1989, y en su mayoría con un aglutinante principal de tipo alquídiconitrocelulósico y en algunos casos acrílico. Existen pocos estudios de caracterización de materiales en los que se traten pinturas en espray de los setenta, ochenta y noventa, por lo que continúa siendo un campo por explorar. Encontramos alguna referencia en investigaciones sobre materiales empleados por artistas de renombre, como los realizados sobre los materiales encontrados en el estudio de Bacon, entre los que se incluyeron tres tipos de pintura en espray de diferentes colores, de las marcas Krylon $^{\circledR}$, U-Spray y la francesa peinture aerosol, en las que se identificó para la primera un aglutinante principal de tipo acrílico (metil-metacrilato/butil-metacrilato), para la segunda uno de tipo vinílico y en la tercera resinas alquídicas y nitrocelulósicas (Russell et al, 2012: 199).

Las complejas formulaciones de las marcas para grafiti y arte urbano actuales combinan la presencia de un aglutinante principal, una resina sintética polimérica, otros ligantes secundarios, generalmente otras resinas sintéticas que mejoran algún aspecto de la pintura, cargas y extendedores, pigmentos de diferente composición, aditivos con distintas funciones y el vehículo: diversos solventes orgánicos, agua y alcoholes y como propelentes hidrocarburos derivados del petróleo, como propano, n-butano y éter dimetílico.

La información suministrada por las empresas productoras es muy limitada y genérica. En las marcas más populares se encuentran principalmente dos sistemas: con base solvente y con base acuosa-alcohólica, siendo el primero el más común, ya que hasta la fecha apenas se localizan tres líneas de producto específico del segundo tipo: ONE4ALL ${ }^{\mathrm{TM}}$ Acrylic de Molotow MTN water-based de Montana Colors, introducida en 2014 y la reciente gama de Ironlak Sugar ${ }^{\circledR}$.

En cuanto a sus componentes, atendiendo únicamente a la información literal suministrada en sus últimas fichas técnicas vemos que $C L A S H^{\circledast}, F L A M E T M$, la gama original Ironlak ${ }^{\circledast}$, Scribo $^{\circledast}$, Fresh Painty Kobra ${ }^{\circledast}$, nombran comoligante una resina acrílica (sin especificar más y en un medio de disolventes orgánicos y cetónicos variados). en el caso de Montana ${ }^{T M}$ cans en su gama Gold, un aglutinante acríliconitrocelulósico, en la Black una laca "nitrocombinada", mientras en la White una resina "sintética". Por otra parte las gamas de Montana Colors, Alien, 94, Hardcore y TNT identifican como ligante resinas alquídicas modificadas y en el caso de la gama de base acuosa-alcohólica una resina de poliuretano modificada, mientras que las Sugar ${ }^{\circledR}$ de Ironlak refieren un aglutinante acrílico, al igual que la gama Molotow one4all ${ }^{T M}$ acrylic, frente a la gama one 4 all ${ }^{T M}$ original y la High Pressure con aglutinantes nitro-alquídicos (ver Tabla1).

Algunas incorporan pigmentos especialmente resistentes a la acción de la luz, que suelen ser fácilmente identificables en muchas marcas, a través de sus fichas técnicas e incluso bloqueadores de luz UV, como CoversAll 3 de Molotow ${ }^{T M}$.

En algunos de los pocos estudios de caracterización de pinturas en espray realizados hasta la fecha, en el campo de las ciencias forenses (Buzzini y Massonnet, 2004; Ryland, 2010) y más recientemente en ciencias aplicadas a la conservación y restauración del patrimonio (Sanmartin et al, 2014; Germinario et al, 2015) podemos ver que en todos los casos se señala la complejidad de sus formulaciones y la dificultad de caracterización del material, lo que implica la necesidad de combinar diversas técnicas analíticas para lograr resultados efectivos. Estos estudios muestran que se emplean diferentes ligantes, como aglutinantes principales en las composiciones. En concreto Ryland, tras estudiar 71 tipos diferentes de pintura negra en espray, procedentes del mercado americano, concluye en que sobre todo se emplean resinas alquídicas, muchas veces combinadas con otras resinas sintéticas y establece cinco tipos de ligantes principales para la muestra estudiada: lacas acrílicas, esmaltes acrílicos, lacas nitrocelulósicas y esmaltes alquídicos y epoxídicos y como modificadores más comunes estireno, viniltolueno y uretano (Ryland, 2010: 116). El estudio de Giulia Germinario incluye muestras del sector del grafiti, doméstico y de la automoción 
y establece que las 45 muestras estudiadas, pueden agruparse bajo las siguientes tipologías: resinas alquídicas; alquídicas modificadas, la mayoría con nitrocelulosa y con estireno en algunas; resinas acrílicas modificadas con estireno, y las de base estirenada, que en este estudio coinciden con casi todas las pinturas metalizadas. Tanto en las muestras estudiadas de Montana Colors, como en las de Dupli-Colors ${ }^{\circledR}$ se identifican pequeñas diferencias entre los aglutinantes principales y secundarios en función del color estudiado, aún perteneciendo a una misma línea de producto. En concreto en las muestras MTN Hardcore negro y MTN94 negro, turquesa, naranja y azul se detecta resina alquídica modificada con nitrocelulosa y sin modificar en el rojo, amarillo y blanco de MTN94, así como en todas ellos polivinil fenil cetona como aglutinante secundario (Germinario et al, 2015: 931, 932).

La formulación de pinturas en spray eficaces, con base acuosa se ha experimentado en muchos momentos, como muestran las patentes registradas, ya a principios de los años 80, que reflejan los problemas derivados de la formación de espuma con la presión, las dificultades en la formación posterior del film e incluso de la estabilidad en el bote (Suk, 1981). La gama water-based de Montana en su ficha técnica se identifica con una resina de poliuretano y los análisis con Pirólisis-Cromatografía de Gases-Espectrometría de Masas realizados por los técnicos del Instituto de Restauración del Patrimonio revelan la presencia de isocianato, derivados de éste y compuestos nitrogenados propios de una resina de tipo poliuretanoy de un pigmento de tipo azo. Con la introducción de esta línea de productos, así como los one 4 all ${ }^{T M}$ acrylic de Molotow y los Sugar ${ }^{\circledast}$ de Ironlak $^{\circledast}$ es probable que si las prestaciones convencen a los usuarios acaben imponiéndose en la vertiente más artística, por su comodidad para el usuario y su respeto al medio ambiente.

\subsection{Rotuladores o marcadores}

\subsubsection{Orígenes}

Los rotuladores constituyen una de las herramientas básicas vinculadas al grafiti y en concreto a las firmas estilizadas o tags.

A pesar de que existen numerosos antecedentes en relación a patentes de artilugios parecidos a los actuales (Newman, 1910; Passkatch, 1926), se suele identificar su invención con la de 1951 de Rosenthal, que daría pie a la compañía Magic Marker Corporation (Rosenthal, 1951), desbancando a los clásicos modelos de acero inoxidable.

Desde su invención y popularización de los sesenta en adelante ha sido una herramienta fundamental para los escritores por su comodidad, facilidad de transporte y accesibilidad, optando siempre por los modelos indelebles orientados al sector de la rotulación y el marcaje industrial y los permanentes de oficina. Al igual que ocurría con la pintura en espray eran muchas veces sustraídos de los comercios y pronto se ingeniaron artilugios caseros que imitaban los sistemas comerciales. Estas herramientas permitían grafiar el nombre con un trazo continuo, de un ancho considerable y con la posibilidad de generar un estilo propio. Aún hoy este tipo de "rotuladores" son conocidos como mops.

La evolución del sector ofrece en la actualidad una gama de productos que los artistas emplean no sólo para los tags, sino también para el retoque de piezas o para aportar determinados efectos en composiciones más complejas.

\subsubsection{Marcas utilizadas}

Hasta el desarrollo del rotulador, tal y como lo conocemos, solían utilizarse instrumentos de acero inoxidable que utilizaban diferentes acabados en su punta para hacer trazos más o menos anchos, como los drawlet pens que comercializaba Esterbrook. Las primeras marcas que aparecen en el mercado y se popularizan por sus prestaciones son, entre otras, Magic Markers ${ }^{\circledR}$, Dri Mark, Edding ${ }^{\circledR}$, Pentel $^{\circledR}$ y Sharpi ${ }^{\circledast 7}$. Algunas de las más empleadas por los primeros grafiteros serán además de las citadas, el Marko ${ }^{\circledR}$ Permanent, Marks-A-lot ${ }^{\circledR}$, Pilot, Niji ${ }^{\circledR}$, Marvy $^{\circledR}$ y los rellenables Mini-Wide y Ultra Wide ${ }^{T M}$.

Los marcadores caseros se realizaban con todo tipo de recipientes, manipulados para colocar en su punta una esponja o fieltro, como los de los borradores de encerado y se rellenaban con tintas industriales. De esos intentos derivará una de las marcas actuales más conocidas en la actualidad, introducida por el grafitero de los noventa Craig Costello; el éxito que tuvo su tinta casera, confeccionada con papel calcográfico y alcohol, conocida como Krink dio lugar a la fundación de la empresa Krink ${ }^{\circledR}$ Inc., compañía que vende tanto tinta, como rotuladores con diferentes puntas para el mundo del grafiti y recipientes para rellenarlos. Como recogen diversas entrevistas, otras tintas industriales procedían del sector de la rotulación, el calzado y las lacas de bombillas. Una de las más apreciadas por su dificultad de eliminación fue la tinta Inferno, nombre que sigue utilizándose en tiendas especializadas en grafiti y street art. Otras muy utilizadas, especialmente en el sector americano eran Flo-master ink, Marsh ${ }^{\circledast}$ y Garvey Ink (CMC crew, 2016).

Los rotuladores de pintura Posca introdujeron ya en 1983 una gama cromática variada con colores cubrientes, características que han imitado varios años después otras marcas especializadas en grafiti y arte urbano, como Molotow y Montana Colors, entre otras. En la actualidad casi todas las empresas que tienen gamas específicas para grafiti y arte urbano producen también líneas de marcadores. Algunas de las más valoradas, además de las ya mencionadas, son la alemana On The $\operatorname{Run}^{\circledast}$, que comercializa marcadores específicos desde 1997, incorporando distintos modelos, algunos míticos 


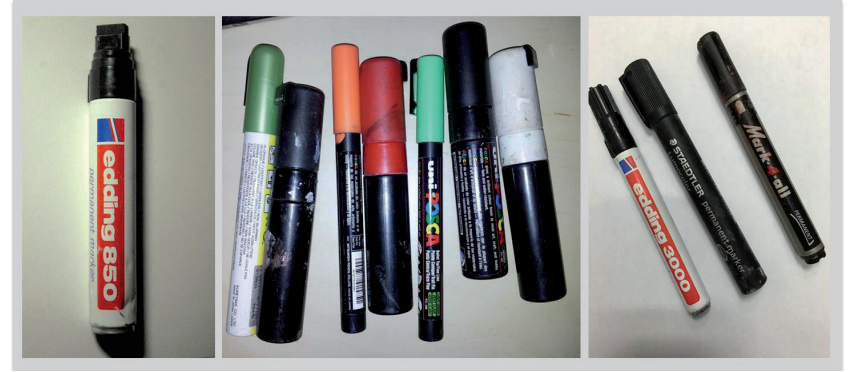

Figura 5. Distintos tipos de rotuladores permanentes empleados para tags y retoque de arte urbano. Cortesía de Novelty aerosoles Facebook https://www.facebook.com/Novelty-aerosoles.

como el Hard to Buff en 1998 o el Flow Pen en el 2000, Grog $^{\circledR}$ y Markwell, empresa americana que introdujo los primeros crayones. Todas ellas ofrecen varios modelos de rotuladores y squeezers, así como tintas y pinturas diversas con las que rellenarlos y puntas intercambiables y renovables. [Figura 5]

\subsubsection{Naturaleza de sus componentes}

La mayoría de rotuladores se basan en el uso de un recipiente que se llena de un líquido, teñido o pigmentado, que, o bien es absorbido por capilaridad hacia la punta, que puede estar hecha con diferentes materiales, con distintos tamaños y acabados, o bien utilizan una válvula dosificadora con una punta realizada también con materiales diversos.

La tecnología que utilizan, así como las formulaciones de la tinta o pintura que contienen han ido modificándose ampliando sus posibilidades de aplicación y orientando sus características hacia el mercado que cada marca ha considerado más conveniente. En los sesenta y setenta el marcaje industrial y de oficina ofrecía rotuladores de tintas permanentes y escasos colores, en disolventes orgánicos, con xileno y tolueno, y el sector escolar y artístico, con tintas borrables, en sistemas al agua poco tóxicos y con una gama de colores más amplia.

Alguna de las tintas míticas empleadas para rellenar los rotuladores caseros, como las Flo-Master contenían plomo, por lo que dejaron de fabricarse.

Estas tintas han ido depurando su composición, eliminando en la medida de lo posible los componentes más tóxicos e incorporando más pigmentos y colorantes. La evolución de los sistemas de aplicación ha permitido incluir pinturas basadas en resinas acrílicas mucho más cubrientes, aunque nuevamente la información suministrada en relación a sus composiciones resulta insuficiente.

Estudios recientes se han interesado en la identificación de los componentes más habituales en una muestra de rotuladores permanentes, identificando cuatro tipos de ligantes principales, en concreto: resinas acrílicas y metacrílicas (modificadas con estireno), generalmente en emulsión acuosa; resinas cetónicas; resinas fenólicas y resinas alquídicas, (Van der Werf et al, 2011: $3486,3487,3488)$. Actualmente se sigue investigando en esta línea con el fin de elaborar una base de datos en relación a estos materiales concretos, que facilite su identificación, pero todavía está en proceso.

En el mercado actual encontramos principalmente dos tipologías de rotuladores orientadas al sector del grafiti:

- los de pintura (con base acuosa de naturaleza acrílica, con base alcohólica y resinas no especificadas y con base solvente, similar a la de las pinturas en espray)

-los de tinta, con base alcohólica o solvente.

La mayoría de ellos son fácilmente eliminables con disolventes cetónicos, por lo que algunas marcas ofrecen barnices protectores que, en algunos casos, además facilitan la compatibilidad con otros productos subyacentes. Los que utilizan pinturas similares a las que contienen los esprays y algunas de las gamas especialmente diseñados para realizar tags suelen contener tintas muy permanentes y penetrantes, con escasos colores, predominando el negro y el rojo. A pesar de la amplia oferta existente algunos prefieren seguir utilizando sistemas caseros y tintas difíciles de eliminar, que penetran más en los soportes porosos e incorporan breas y alquitranes, como se ve en diversos foros en los que comparten recetas ${ }^{8}$.

Con respecto a las pinturas comerciales que se ofrecen para rellenar los dispositivos podemos ver, además de tintas industriales, las mismas tipologías de materiales que cada casa comercial utiliza en los propios rotuladores.

\subsection{Pintura doméstica}

\subsubsection{Orígenes}

Las primeras pinturas que se utilizaron antes de que los sprays ocuparan todo el protagonismo fueron pinturas de tipo industrial, fáciles de conseguir y difíciles de eliminar. La industria de la pintura se ha desarrollado principalmente en el siglo XX al tiempo que la tecnología de producción de las resinas sintéticas.

Los escritores sólo las utilizarán de una forma puntual, sin embargo a partir de los ochenta son muy habituales. Obras míticas de Keith Haring y otros muchos están realizadas con pintura, brocha y rodillo. Todas las que integran la East-Side-Gallery de Berlín, están pintadas de este modo, al igual que muchas de las que realizan artistas actuales de renombre internacional como Blu o Escif. De hecho en la últimas ediciones del festival Poliniza y Poliniza-Dos de la Universitat Politècnica de 
València, queda patente la tendencia de los participantes a decantarse por el uso de pintura de pared, sola o combinada con otras técnicas, como papeles e impresiones digitales adheridas. [Figura 6]

\subsubsection{Marcas utilizadas}

Hablar de marcas en este caso es extenso al tratarse de un sector comercial tan amplio y con un desarrollo tan grande a lo largo de las últimas décadas.

Repasando algunos estudios realizados sobre su evolución (Stavenden 2011; Dresgen 2014) es posible rastrear la aparición de ciertas empresas clave, como Du-Pont o Sherwin-Williams, que irán patentando marcas y firmando licencias de producción o distribución en otros países en fechas muy concretas, lo que ayuda a determinar el momento en el que un artista dispone de un material determinado. Sin embargo estos estudios precisan ser complementados con otros más específicos referidos a otros países, entre ellos España.

Se tiene constancia del uso de pinturas decorativas por alguno de los artistas más influyentes del siglo XX, como Picasso, Bacon o Jackson Pollok, por su disponibilidad, pero también por las cualidades estéticas que ofrecían. Marcas como Carsons, Dulux y Ripolin aparecen en diversos estudios, como los presentados en el simposium celebrado en Marsella "From Can to Canvas: Early uses of house paints by Picasso and his contemporaries in the first half of the 20th century," en 2011, recogidos en dos números especiales del Journal of the American Institute for Conservation en el 2013.

En el arte urbano las pinturas más usadas suelen proceder del ámbito de la pintura de paredes, por su facilidad de adquisición, uso, manejo y baja toxicidad, así como por el rendimiento competitivo que ofrecen. Hay muy pocos estudios que se hayan preocupado de este ámbito y las múltiples entrevistas que se les hace a los artistas pocas veces incluyen el tema de los materiales y las marcas de pintura utilizadas. Lo que sí se puede apreciar es que, en general, emplean las pinturas que les son cercanas y están acostumbrados a manejar, o bien las que les son proporcionadas en el lugar en el que van a realizar la obra, en el caso de exhibiciones y festivales (Sánchez, 2016).

Actualmente al igual que ocurre en otros sectores industriales, las pinturas de construcción y decoración están organizadas bajo grandes holdings que controlan el sector y aglutinan a las diferentes marcas y filiales, como Azko Nobel en Holanda, o Sherwin-Williams en Estados Unidos.

\subsubsection{Naturaleza de sus componentes}

La industria de las pinturas se ha desarrollado a lo largo del siglo $\mathrm{XX}$, al ritmo marcado por la investigación en su química y tecnología. Puesto que importantes artistas convencionales del siglo XX incorporan en sus obras estas pinturas por experimentación, posibilidades plásticas y por supuesto por su accesibilidad, su estudio se está tratando con cierta profundidad en la conservación y restauración de arte contemporáneo. Las primeras pinturas industriales en producirse fueron las pinturas nitrocelulósicas y en pocos años irían incluyéndose los esmaltes basados en pinturas alquídicas, vinílicas y acrílicas, todas ellas con base disolvente, hasta la aparición de los látex sintéticos.

En las décadas de los ochenta y noventa, la industria ya había evolucionado mucho. Las dispersiones acuosas de resinas sintéticas o látex, por sus características, se habían impuesto en la pintura doméstica de pared y era muy fácil encontrarlas en droguerías y grandes almacenes, así

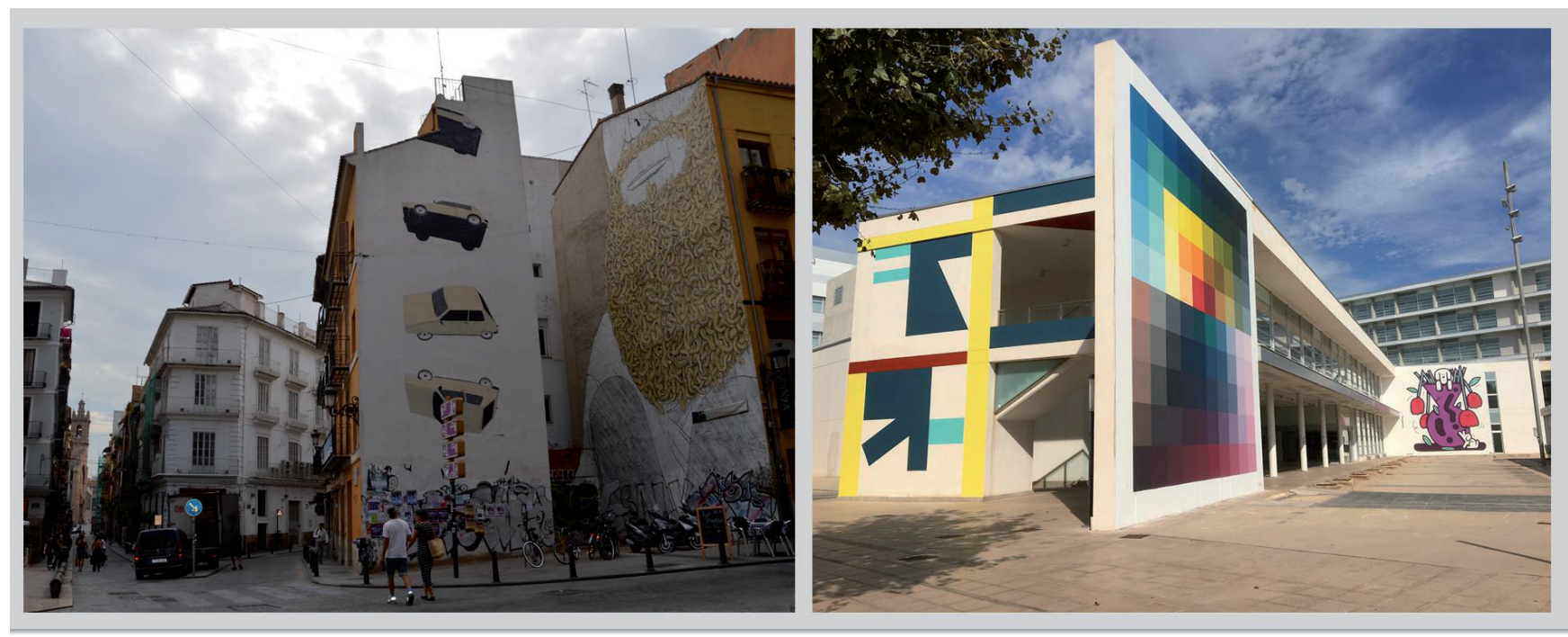

Figura 5. Murales de Escif y Blu en la plaza del Tossal, Valencia. Intervenciones de ElTono, Alberonero y Edjin para Poliniza-Dos XI Trobada d'art urbà, Universitat Politècnica de València. 
como en tiendas específicas de pinturas. Dependiendo de la marca y destino de uso (fondos, acabados, interior o exterior) sus aglutinantes y fórmulas cambiaban, pudiendo encontrar, sobre todo, emulsiones de acetato de polivinilo, emulsiones de estireno-butadieno, copolímeros acrilvinílico y resinas acrílicas para pinturas de exterior, con distintos componentes y proporciones de ingredientes (Learner, 2004). En general son pinturas en las que, sobre una base acuosa se mantienen en suspensión partículas sólidas de diferentes polímeros. Al perder el agua, ya sea por evaporación o por absorción del soporte, y debido a la creciente tensión superficial que se produce al aproximarse las partículas, éstas se fusionan en frío alrededor de las partículas de pigmento, deformándose plásticamente gracias a los agentes coalescentes y compactándolo (Giudice, 2009). Las formulaciones diferentes intentan compensar las composiciones para conseguir unas determinadas características en la película de pintura seca, además de asegurar su estabilidad durante el circuito comercial hasta que son utilizadas.

Estos serán los materiales que con más facilidad podrán encontrarse en el arte urbano realizado con pintura de pared, aunque las formulaciones específicas dependerán del momento concreto de comercialización, la empresa que las produzca o distribuya y la zona geográfica. Por ejemplo en tres pinturas de Keith Haring realizadas en la década de los 80 en Melbourne (1984), París (1987) y Pisa (1989) se identificaron aglutinantes muy diferentes, todos ellos habituales en pinturas sintéticas de emulsión acuosa: vinílicos, acrílicos y alquídicos, en el mural de Collingwood, resinas vinílicas con pequeñas cantidades de $\mathrm{VeoVa}^{T M}$ como plastificante en el Hospital Necker de París, y un copolímero estireno/n butilacrilato en el mural de Tuttomondo en Pisa (La nasa, 2015). La marca de pinturas empleada en este último fue Amphibolin paints de la casa Caparol (Rava et al, 2015). Las tres obras han sido restauradas y cada una se encontraba en un estado diferente, debido no sólo a los materiales empleados, sino también a la interacción entre los distintos estratos, las condiciones ambientales del entorno y a la propia historia de la obra.

Hoy en día continúan utilizándose este tipo de pinturas en dispersión acuosa, tanto para utilizarlos como base, como para emplearlos en la ejecución de la obra, solos o combinados.

Son pinturas parecidas a las acrílicas y vinílicas de tipo artístico pero su formulación está orientada hacia el mercado y uso al que están destinadas, con unos requisitos de calidad y aplicabilidad muy específicos y no necesariamente coincidentes con los artísticos. En general constan de una cantidad mayor de cargas y extendedores, lo que repercute lógicamente en su estabilidad y comportamiento, con pigmentos con distintos grados de resistencia a la luz, así como aditivos que permiten su almacenamiento y distribución en cantidades mayores, pero que, lógicamente, también interfieren en su proceso de envejecimiento y degradación.
A pesar de que estos son los materiales más comunes, no hay que olvidar que los artistas pueden acceder con gran facilidad a multitud de pinturas, tanto del sector artístico como industrial que, en un momento dado y por múltiples circunstancias, pueden resultarles de interés y ser incorporadas en sus creaciones.

\section{Conclusiones}

El conocimiento de los materiales constitutivos de las obras que pretenden ser conservadas es imprescindible. Tal y como se ha demostrado, el arte urbano es mucho más que pintura en espray.

Los materiales pictóricos empleados, tanto en las pinturas en espray, como en los rotuladores y pintura doméstica son muy diversos, por lo que a la hora de documentar estas obras se debería atender a las tipologías mencionadas, intentando incluir no sólo la marca, sino, a ser posible, la gama específica utilizada, con la referencia de color.

Los estudios publicados en relación a la introducción de las pinturas industriales y domésticas en los mercados europeos resultan insuficientes para abordar una posible conservación por lo que sería conveniente emprender líneas concretas en este sentido, al igual que completar la caracterización de pinturas en espray de diversas épocas y marcas comerciales.

También se ha podido comprobar que las entrevistas revisadas, aunque en algunos casos incluyen datos importantes, casi nunca se centran en aspectos relativos a los materiales que utilizan, por lo que se detecta la necesidad de plantear estudios estadísticos en esta línea.

Dada la dificultad para la identificación exacta de los componentes utilizados en las formulaciones modernas de pintura, que precisan del uso de varias técnicas de análisis combinadas y puesto que parte de la información puede obtenerse directamente del fabricante, resulta de especial relevancia, en algunas tipologías de arte urbano, potenciar la documentación de las obras en un momento cercano a su creación, de modo que permita recoger la información relativa a los materiales empleados, contactando incluso con las empresas suministradoras para incorporar los datos precisos para su futura conservación, caso de ser necesaria.

La estabilidad de las pinturas domésticas habituales expuestas al exterior es bastante limitada, ya que está pensada para una duración acorde al mercado de la construcción, en el que los estratos se reponen cada cierto tiempo, como parte de un sistema de mantenimiento, por lo que sería conveniente orientar investigaciones específicas hacia sistemas compatibles de protección. Considerando la controversia actual con respecto a 
la conveniencia de determinadas metodologías de limpieza sobre las pinturas acrílicas sería conveniente plantear los problemas que podrían generarse en estas superficies, muchos menos resistentes a priori y con un porcentaje de cargas y aditivos mayor.

Los problemas técnicos que puedan presentarse pueden llegar a ser muy complejos, pero no por ello irresolubles cuando se cuenta con toda la información posible.

Por todo ello parece necesario estudiar modos de documentación de estas obras, que comiencen en su propio proceso de generación, especialmente en las obras que reconocemos como comisionadas, y así poder establecer, un proceso de conservación preventiva, que pueda facilitar, en el caso de ser necesario, la intervención concreta de protección o incluso de restauración.

\section{Notas}

[1] programa fundado en 1986 por Jane Golden, https://www. muralarts.org [consulta 28-09-15].

[2] El plan de actuación contra las pintadas vandálicas del ayuntamiento de Salamanca incluye en su página 43 un epígrafe denominado: Fomento del grafiti autorizado, accesible en http://www.urbanismo.aytosalamanca.es/es/ archivourbanistico/docs/Plan_actuacion_contra_pintadas_ vandalicas.pdf [consulta 12-07-16].

[3] https://www.facebook.com/staco.street.art.conservators/ [consulta 12-08-16].

[4] http://www.seymourpaint.com/history/ [consulta 17-0716.

[5] Rust Oleum: empresa fundada por Robert Fergusson en 1921 en Nueva Orleans para la producción y comercialización de recubrimientos protectores, en 1932 RUST -OLEUM Paint Co.) En 1959 llega al mercado europeo abriendo una fábrica en Holanda. Actualmente es una filial de RPM Industrial Inc. http://www.rustoleum.com/about-rust-oleum/our-history [consulta 22-05-2015]; Krylon: compañía fundada en 1947 en Filadelfia por Howard E. Kester, bajo el nombre corporativo de Krylon, Inc. para la producción y comercio de protectores en espray de naturaleza acrílica destinados al sector artístico. A principios de la década de los cincuenta reorienta su producción hacia las pinturas de decoración. Actualmente forma parte del grupo Sherwin-Williams, http://www.krylon. com/about/[consulta 22-05-2015].

[6] Facebook Novelty aerosoles, https://www.facebook.com/ Novelty-aerosoles-238824393395/?fref=ts [consulta 22-0616] y Flickr Oldschoolmadrid, https://www.flickr.com/groups/ oldschoolmadrid/members/. [consulta 22-06-16].

[7] Magic Markers Corporation: compañía fundada en 1953,
Estados Unidos, http://www.magicmakersinc.com [consulta 17-06-16]; Drimark Products Inc.: compañía fundada en 1957, Estados Unidos, http://www.drimark.com [consulta 17-0616]; Edding S.L.: compañía fundada en 1960, Holanda http:// www.edding.com [consulta 17-06-16]; Pentel: compañía fundada en 1963, Japón, http://www.pentel.com (acceso 1706-16); Sanford: compañía fundada en 1964, Estados Unidos, https://www.sharpie.com/en-US/about-us. [consulta 17-0616].

[8] BettasGalicia (2011) http://tintasdegraffiticaseras.blogspot. com.es [consulta 25-06-16]

\section{Bibliografía}

ABARCA, J. (2010). El postgraffiti, su escenario y sus raíces: graffiti, punk, skate y contrapublicidad. Tesis doctoral. Madrid: Universidad Complutense de Madrid, Dpto. de Dibujo.

BERTI, G. (2009). Pioneros del Graffiti en España. Valencia: Servicio editorial de la Universitat Politècnica de València.

BEERKENS, L., MAGER, S. (2005): “Keith Haring: art or graffiti. The restoration of Keith Haring's Drawing on elevator (1986) in the Art Academy Utrecht", en Beiträge zur Erhaltung von Kunstund Kulturgut , 2: 114-122.

BLANCH, I. (2015). "East Side Gallery. Proyecto Internacional sobre el muro de Berlín", en Conservation issues in modern and contemporary murals, Sánchez, M., Shark, W., Fuster, L. (editores). Londres: Cambridge Scholars Publishers, 27-39.

BUZZINI, P., MASSONNET, G (2004). "A market study of Green spray paints by Fourier transform infrared (FTIR) and Raman spectroscopy", en Science\&justice, 44: 123-131.

CARLSSON, B., LOUIE, H. (2013): Street Art. Recetario de técnicas y materiales del arte urbano, Gustavo Gili, Barcelona (versión traducida por Darío Giménez de la original Street Art Cookbook: a Guide to Techniques and Materials, Dokument Press, 2010).

CASTLEMAN, Craig. Los Graffiti, Hermann-Blume, Madrid, 1987.

CIANCABILLA, L. (2015). The sight gallery : salvaguardia e conservazione della pittura murale urbana contemporanea a Bologna. Bolonia: Bolonia University Press.

CHALFANT, H., PRIGOFF, J. (1987), Spray Can Art, Londres: Thames\& Hudson.

FIGUEROA, F., GÁLVEZ, F. (2002). Madrid graffiti. Historia del graffiti madrileño 1982-1995. Málaga: Grupo Editorial Megamultimedia.

FIGUEROA, F., GÁLVEZ, F. (2015) Firmas, muros y botes, autoedición. 
GASTMAN, R., NEELON, C. (2011): History of American Graffiti. Nueva York: Harper Collins Publishers.

GANZ, N. (2010): Grafiti. Arte urbano de los cinco continentes. Barcelona: Gustavo Gili.

GIUDICE, C., PEREYRA, A. (2009). Tecnología de pinturas y recubrimientos: componentes, formulación, manufactura y calidad. Buenos Aires: Edutecne.

GÓMEZ, J. (2014). 25 años de graffiti en Valencia: aspectos sociológicos y estéticos, Tesis doctoral, Universidad de Valencia.

LACHLAN MCD. (2006): In Praise of 70K. "Cultural Heritage and Graffiti Style", Continuum, 20: 471-488.

LA NASA, J., ORSINI, S., DEGANO, B., RAVA, A., MODUGNO, F., COLOMBINI, M.P.(2016). "A chemical study of organic materials in three murals by Keith Haring: a comparison of painting tecniques", Microchemical journal, 124: 940-948.

LEARNER, T. (2004). Analisys of Modern Paints. Los Ángeles: Getty Publications.

LEWISOHN, C. (2008). Street Art, The graffiti revolution. Londres: Tate Publishing.

RAVA et Al (2015). "Keith Haring in Pisa: cleaning and protection of an acrylic painting in an outdoor environment" en Conservation issues in modern and contemporary murals. Londres: Cambridge Scholars Publishers, 184-208.

ROSKO, D (2016): Aerosols (oldschool cans). Autoedición

RUSSELL, J., SINGER, B., PERRY, J, BACON, A (2012). “Investigation of the materials found in the studio of Francis Bacon (19091992)", en Studies in Conservation, 57: 195-206.

RYLAND, S. (2010). "Discrimination of Retail Black Spray Paints", en Journal of American Society of Trace Evidence Examiners, 1: 109-126.

SÁNCHEZ, M. (2016). "Arte urbano: selección de materiales y consecuencias" Mural Street Art Conservation, 3: 40-43.

SANMARTÍN, P., CAPPITELLI, F., MITCHELL, R. (2014). "Current methods os graffiti removal: A review", Construction and Building Materials, 71: 363-374.

SHANGRAW, R. (1971:11). Principles of Aerosol Technology. Nueva York: Reinhold.

STANDEVEN, H. (2011). House paints, 1900-1960 History and use. Los Ángeles: Getty Publications.

VAN DER WERF, I., GERMINARIO, G., PALMISANO, F., SABBATINI, L. (2011) "Characterisation of permanent markers by pyrolysis gas chromatography-mass spectrometry", en Analytical and Bioanalalytical Chemistry, 339: 3483-3490.
WACLAVEK, A. (2011) Graffiti and Street Art, Nueva York: Thames \& Hudson.

\section{Consultas Online}

ABPLANALP, R. (1953). Valve mechanism for dispensing gases and liquids under pressure https://www.google.com/patents/ US2631814 (acceso 22-07-16).

CMC crew (2016), entrevista a Crow http://capmatchescolor. $\mathrm{com} / \mathrm{crow} /($ acceso 15-08-16).

CMC crew (2016), entrevista a Luze, http://capmatchescolor. com/luze/(acceso 15-08-16).

MORENO, J. (2016). 22. Novelty, en madridmepriva, https:// madridmepriva.wordpress.com/2016/02/26/22-novelty (acceso 11-06-16)

NEWMAN, L (1910). Marking Pen, https://www.google.com/ patents/US946149 (acceso 22-07-16).

PASSKATCH, B (1926): Fountain Pen Brush http://www.google. ch/patents/US1601596 (acceso 22-07-16).

ROSENTHAL, S. (1951). Felt pack construction of pens US 3050768 A https://www.google.com/patents/US3050768 (acceso 22-07-16).

SENDRA, A (2007). R.E.A. una historia de graffiti a valència, treballarcansa, https://www.youtube.com/ watch?v=aO7mjclbCdQ (acceso 15-4-16).

SCHILLING, J. (2012). Preserving art that was never meant to last, http://www.dw.com/en/preserving-art-that-was-nevermeant-to-last/a-15933463 (acceso 12-07-16).

SUK, A. (1981). Aerosol water-based paint composition US $4265797 \quad$ A, http://www.google.ch/patents/US4265797 (acceso 24-07-16).

WEIDE, R. (2006). "How an object become a subculture", en Objects, Consumption and Desire, http://www.nyu.edu/classes/ bkg/objectsblog/archives/spray.pdf (acceso 20-03-15). 


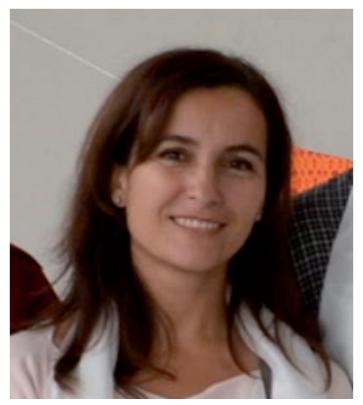

\section{Mercedes Sánchez Pons}

Departamento de Conservación y Restauración de Bienes Culturales de la UPV mersanpo@crbc.upv.es

Doctora por la Universitat Politécnica de Valencia, en el programa de Conservación y Restauración de Bienes Culturales en 2002 y Licenciada en Bellas Artes con la especialidad de Restauración. Desde 2003 es profesora titular del Departamento de Conservación y Restauración de Bienes Culturales de la UPV en los títulos de Grado y Máster. Responsable desde 2006 de la asignatura de máster Conservación y Restauración de Murales Contemporáneos ha dirigido numerosas tesis de grado y máster en relación a este tema.

Forma parte del Grupo de Investigación Taller de análisis e intervención en Pinturas Murales del Instituto de Restauración del Patrimonio de la UPV y pertenece al Micro-Clúster de Investigación (MCI) "Globalización, turismo y patrimonio" en International Campus of Excellence VLC/ CAMPUS.

Ha dirigido y participado en numerosos proyectos de investigación, catalogación e intervención de pinturas murales, nacionales e internacionales, destacando entre los más recientes la restauración de los murales de la iglesia de San Nicolás en Valencia y el Proyecto Europeo Ewaglos: european ilustrated glossary of conservation terms for wall painting and architectural surfaces. Responsable junto a Will Shank y Laura Fuster del congreso internacional Modern and Contemporary Mural Paintings (mcmp2012) es también coeditora y autora del volumen Conservation Issues in Modern and Contemporary Murals (Cambridge Scholars Publishing, 2015).

Desde 2005 forma parte del equipo de Decanato de la Facultad de Bellas Artes de Valencia, como vicedecana de Relaciones con la Empresa, Cátedras de Empresa y en la actualidad con el cargo de Secretaria del centro. 